\title{
Ligand-binding characteristics of recombinant amino- and carboxyl-terminal fragments of human insulin-like growth factor-binding protein-3
}

\author{
M Galanis ${ }^{1,2}$, S M Firth ${ }^{3}$, J Bond ${ }^{3,4}$, A Nathanielsz ${ }^{1,2}$, \\ A A Kortt ${ }^{1,2}$, P J Hudson ${ }^{1,2}$ and R C Baxter ${ }^{3,4}$ \\ ${ }^{1}$ CSIRO Division of Health Science and Nutrition, 343 Royal Parade, Parkville, Victoria 3052, Australia \\ ${ }^{2}$ CRC for Diagnostic Technologies, 343 Royal Parade, Parkville, Victoria 3052, Australia \\ ${ }^{3}$ Kolling Institute of Medical Research, University of Sydney, Royal North Shore Hospital, St Leonards, New South Wales 2065, Australia \\ ${ }^{4}$ CRC for Diagnostic Technologies, Royal North Shore Hospital, St Leonards, New South Wales 2065, Australia \\ (Requests for offprints should be addressed to R C Baxter, Kolling Institute of Medical Research, Royal North Shore Hospital, \\ St Leonards, New South Wales 2065 Australia; Email: robaxter@med.usyd.edu.au) \\ (M Galanis and S M Firth contributed equally to this work)
}

\begin{abstract}
Insulin-like growth factor-binding protein-3 (IGFBP-3) is a member of a family of structurally conserved proteins (IGFBP-1 to -6) which act as carriers and regulators of the mitogenic peptide hormones IGF-I and IGF-II. Members of the IGFBP family share conserved cysteine-rich aminoand carboxyl-terminal regions. The amino-terminal domain of these proteins is recognised to contain an IGF-binding determinant, but evidence to support a binding site in the carboxyl-terminal region of the protein is less rigorous. To further investigate this, we have synthesised both the amino-terminal (residues 1-88; N-88) and carboxyl-terminal (residues 165-264; C-165)
\end{abstract}

domains of human IGFBP-3 in bacteria, as fusion proteins with a carboxyl-terminal FLAG peptide. Although only C-165 showed binding to IGF-I and -II by solutionbinding assays, both N-88 and C-165 demonstrated binding to IGF-I and -II by biosensor analysis albeit with reduced affinities compared with full-length IGFBP-3. Only the carboxyl-terminal fragment (C-165) was able to form hetero-trimeric complexes with IGF-I and the acid-labile subunit (ALS). We conclude that the carboxylterminal domain of IGFBP-3 contains an IGF-binding determinant and can form ternary complexes with ALS.

Journal of Endocrinology (2001) 169, 123-133

\section{Introduction}

Peptides of the insulin-like growth factor family (IGF-I and IGF-II) are found associated with IGF-binding proteins (IGFBPs) in the circulation and in other body fluids (Rajaram et al. 1997). The human IGFBP family consists of six proteins, designated IGFBP-1 to IGFBP-6, with three domains of approximately equal size. The aminoterminal and carboxyl-terminal domains are cysteine-rich and show considerable sequence similarity among all IGFBPs. The central domain is devoid of conserved cysteine residues and is different in each IGFBP. The most abundant IGFBP, IGFBP-3, consists of an amino-terminal domain spanning residues 1 to 88 , a central non-conserved domain spanning residues 89 to 184 and carrying glycosylation, phosphorylation and proteolysis sites, and a carboxyl-terminal domain which spans residues 185 to 264 (Baxter 1997).

Whereas all six IGFBPs form high-affinity binary complexes with IGF-I and IGF-II, only the complexes with
IGFBP-3 and IGFBP-5 can associate with the glycoprotein acid-labile subunit (ALS) in serum to form ternary complexes of 125-150 kDa (Baxter et al. 1989, Twigg \& Baxter 1998). These ternary complexes, in particular the IGFBP-3 complex, are major carriers of circulating IGFs and are regulated by growth hormone. Human IGFBP-3 is always found in serum in two glycoforms of approximately $40-45 \mathrm{kDa}$; however, mutagenesis to remove the glycosylation sites, or expression in a non-glycosylating system, has no effect on IGF-I binding (Sommer et al. 1993, Firth \& Baxter 1999). Hence, analysis of the IGF-binding affinity of IGFBP-3 constructs expressed in prokaryotic systems, incapable of glycosylating proteins, is valid.

Due to their high sequence homology, it is assumed that the IGF-binding domain structure will be shared among all six IGFBPs. A recent nuclear magnetic resonance analysis of an IGFBP-5 fragment suggested that the major IGF-binding determinant of that protein was in the amino-terminus (Kalus et al. 1998), a similar conclusion to 
that reached by scanning mutagenesis of bovine IGFBP-2 (Hobba et al. 1998). In contrast, naturally occurring carboxyl-terminal fragments of rat and human IGFBP-2 retain considerable affinity for IGF-II (Wang et al. 1988, Ho \& Baxter 1997), raising the possibility of additional, carboxyl-terminal IGF-binding determinants on other IGFBPs.

To identify the IGF-binding domains of human IGFBP-3, we have synthesised a fragment of IGFBP-3 in E. coli that encompasses the amino-terminal domain (residues 1-88), and a carboxyl-terminal fragment (residues 165-264) that includes 20 residues of the central nonconserved region. Solution-binding assays and biosensor analysis reveal that both recombinant IGFBP-3 fragments independently retain the ability to bind IGFs, indicating that separate binding sites exist within the two terminal domains. The carboxyl-terminal fragment has a higher IGF-binding affinity than the amino-terminal domain, and is able to form ternary complexes with IGF-I and ALS.

\section{Materials and Methods}

\section{Reagents}

Oligonucleotides were synthesised using an Applied Biosystems 391 DNA Synthesiser. T4 DNA ligase was from Biotech International (North Ryde, NSW, Australia) and Vent DNA polymerase and restriction enzymes were from New England Biolabs (Beverly, MA, USA). BRESAclean DNA Purification Kit was from GeneWorks (Adelaide, Australia) and QIAGEN Plasmid Mini Kit was from QIAGEN (Hilden, Germany). NitroBind nitrocellulose transfer membrane was from Micron Separations Inc. (Westborough, MA, USA) and ProBlott polyvinylidene diflouride (PVDF) membrane was obtained from PerkinElmer Applied Biosystems (Foster City, CA, USA). Hybridoma cell line KM5-1C7-8-5 for an anti-FLAG antibody (now available as FLYTAG antibody from AMRAD, Boronia, VIC, Australia) was kindly provided by Dr N Nicola (CRC for Cellular Growth Factors and Walter and Eliza Hall Institute, Australia). Horseradish peroxidase-conjugated goat anti-mouse $\operatorname{IgG}(\mathrm{Fc})$ secondary antibody was purchased from Pierce Chemical Company (Rockford, IL, USA) and BenchMark Prestained Protein Ladder was from Gibco BRL Life Technologies (Gaithersburg, MA, USA). Receptor grade recombinant human IGF-I and -II were obtained from GroPep (Adelaide, Australia) and bovine serum albumin (radioimmunoassay (RIA) grade) was from Sigma-Aldrich (Castle Hill, NSW, Australia). The BIAcore 1000 instrument, sensor chip CM5 and surfactant P20 were acquired from BIACORE AB (Uppsala, Sweden).

\section{Strains and media}

Bacterial hosts employed in this study were HB2151 (K12 $\Delta$ (lac-pro) araD nal thi $\mathrm{F}^{\prime}\left\{\right.$ pro $\mathrm{AB}, l a c \mathrm{I}^{\mathrm{q}}$, lac $\left.\left.\mathrm{Z} \Delta \mathrm{M} 15\right\}\right)$ from
Pharmacia (Uppsala, Sweden) and TOP10F' (K12 thi $\mathrm{F}^{\prime}\left\{\right.$ pro $\mathrm{AB} \quad$ lac ${ }^{\mathrm{q}} \quad$ lac $\mathrm{Z} \Delta \mathrm{M} 15 \quad \operatorname{Tn} 10\left(\right.$ Tet $\left.\left.^{\mathrm{R}}\right)\right\} m c r \mathrm{~A} \quad \Delta(m r r-$ hsdRMS-mcrBC) $\quad$ 80lacZ $\Delta 15 \quad \Delta l a c X 74$ deoR $\operatorname{rec} A 1$ araD139 $\Delta$ (ara-leu)7697 galU galK rpsL $\left(\mathrm{Str}^{\mathrm{R}}\right)$ end $A 1$ nup $G$ $\lambda^{-}$) from Invitrogen (San Diego, CA, USA). HB2151 was routinely used for manipulation of DNA during vector construction and strain TOP10F' was used for expression studies. TOP10F' cells were maintained on YT solid media $(0.8 \%$ bacto-peptone, $0.5 \%$ bacto-yeast extract, $0 \cdot 25 \% \mathrm{NaCl}, 1 \cdot 5 \%$ bacto-agar) supplemented with $15 \mu \mathrm{g} / \mathrm{ml}$ (w/v) tetracycline, whilst HB2151 cells were maintained on unsupplemented YT solid media. E. coli transformants were maintained and grown on $2 \times$ YT media supplemented with appropriate antibiotics $(100 \mu \mathrm{g} / \mathrm{ml}$ (w/v) ampicillin and/or $15 \mu \mathrm{g} / \mathrm{ml}$ (w/v) tetracycline) and $1 \%(\mathrm{w} / \mathrm{v})$ glucose. Solid media contained $1.5 \%(\mathrm{w} / \mathrm{v})$ bacto-agar (DIFCO Laboratories, Detroit, MI, USA).

\section{Cloning and manipulation of DNA}

Restriction digestions, ligation reactions and gel electrophoresis of DNA were performed according to standard methods (Sambrook et al. 1989). Electrophoresis of DNA used 1-2\% SeaPlaque low melting point agarose (FMC Bioproducts, Rockland, ME, USA) gels in $40 \mathrm{mM}$ Tris acetate, $1 \mathrm{mM}$ EDTA (pH 8.0). DNA fragments, excised from gels for cloning, were purified using BRESAclean DNA Purification Kit according to the manufacturer's directions. Small-scale preparations of DNA from E. coli were made using QIAGEN Plasmid Mini Kit.

Human IGFBP-3 cDNA was cloned by RT-PCR from a neonatal fibroblast cell line (S M Firth, unpublished data). DNA segments encoding two regions of the human IGFBP-3 cDNA (see Fig. 1A) were generated by PCR amplification using human fibroblast IGFBP-3 cDNA as template and oligonucleotide primers (see Fig. 1B) carrying either a unique in-frame SfiI restriction site ( $5^{\prime}$ primer) or a unique NotI site ( $3^{\prime}$ primer) for subsequent cloning of the PCR products into the expression vector pPOW3 (Power \& Hudson 2000). The construct description and designations are shown in Fig. 1. N-88 denotes the IGFBP-3 amino-terminal domain, spanning residues 1-88 and C-165 denotes IGFBP-3 carboxyl-terminal domain spanning residues $165-264$. Both constructs contain a 22 amino acid $\mathrm{N}$-terminal cleavable pelB secretion signal sequence and a C-terminal 21 residue extension consisting of three alanine residues (resulting from the cloning) and two FLAG octapeptide affinity tags linked by two alanine residues (DYKDDDDKAADYKDDDDK).

DNA constructs were transformed into electrocompetent or $\mathrm{CaCl}_{2}$ competent E. coli cells using standard procedures (Sambrook et al. 1989) and stored at $-70{ }^{\circ} \mathrm{C}$ until required. All constructs were confirmed by nucleotide sequencing. 


\section{A}

\begin{tabular}{|c|c|c|c|c|c|c|}
\hline \multirow{2}{*}{\multicolumn{2}{|c|}{ IGFBP-3 }} & \multicolumn{2}{|c|}{88} & \multicolumn{2}{|c|}{165185} & \multirow[t]{3}{*}{64} \\
\hline & & $\mathrm{N}$-terminal domain & Cent & main & C-terminal domain & \\
\hline $\mathrm{N}-88$ & pelB & $\mathrm{N}$-terminal domain & FLAG & & & \\
\hline C-165 & & & & pelB & C-terminal domain & FLAG \\
\hline
\end{tabular}

B

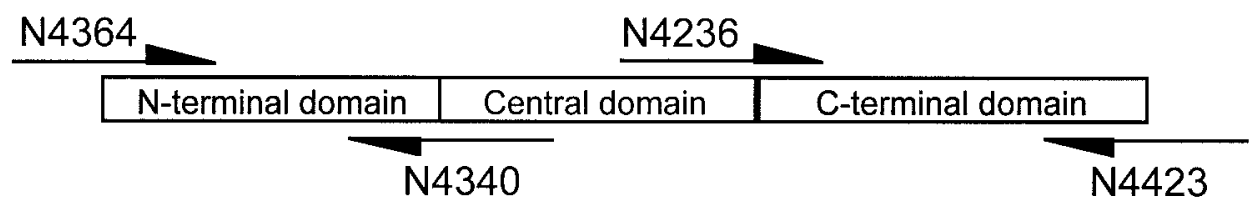

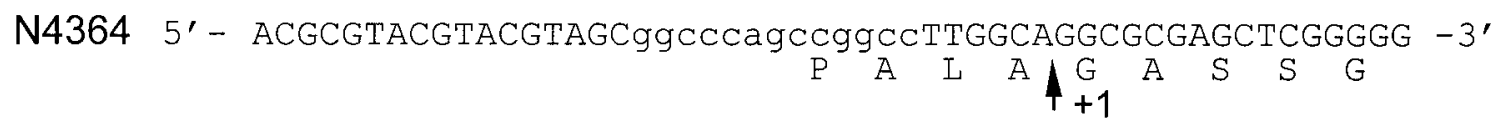

N4236 5' - ACGCGTACGTACGTAGCggcccagccggceTTGGCATCTCAGAGCACAGATACCCAG - 3'

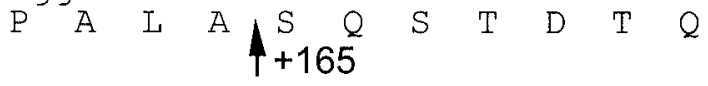

N4340 5'- ATCTtTATAATCTgcggecgCGACGCAGAGGAGCCCGCGGCC -3'

\section{N4423 5'- GCCCATCTTTATAATCTgCggCcgCCTTGCTCTGCATGCTGTA - 3'}

Figure 1 Schematic diagram of the recombinant human IGFBP-3 fragments and oligonucleotide primers used. (A) Schematic diagram of protein constructs corresponding to the $\mathrm{N}$-terminal cysteine-rich domain (amino acids 1-88; denoted $\mathrm{N}$-88) and the C-terminal cysteine-rich domain (amino acids165-264; denoted C-165) cloned and expressed in this study. The genes were expressed with the pelB signal sequence and two C-terminal FLAG octapeptide tag sequences (AAADYKDDDDKAADYKDDDDK). (B) Sequences of oligonucleotide primers used to amplify the gene segments encoding N-88 and C-165 and schematic representation of the regions in human IGFBP-3 cDNA where they anneal. The upstream oligonucleotides incorporate a Sfil site (denoted by lower case letters), whilst the downstream oligonucleotides incorporate a Notl site (denoted by lower case letters), such that all amplified constructs can be cloned into the Sfil/Notl cloning sites of expression vector pPOW3. The amino acid sequence is shown below the nucleotide sequences, and arrows indicate the signal peptidase cleavage site for both constructs.

Protein expression of $\mathrm{N}-88$ and $\mathrm{C}-165$ constructs cloned into pPOW3

Transformed E. coli TOP10F' were grown in $100 \mathrm{ml}$ $2 \times$ YT broth containing $100 \mu \mathrm{g} / \mathrm{ml}(\mathrm{w} / \mathrm{v})$ ampicillin in a 1 litre flask, overnight at $30^{\circ} \mathrm{C}$. On the following day, the overnight culture was used to inoculate $900 \mathrm{ml}$ fresh $2 \times \mathrm{YT}$ containing $100 \mu \mathrm{g} / \mathrm{ml}(\mathrm{w} / \mathrm{v})$ ampicillin to an $\mathrm{OD}_{600}$ of $0 \cdot 2-0 \cdot 5$. The culture was split into $4 \times 1$ litre flasks and incubated at $30^{\circ} \mathrm{C}$ with shaking $(150-200$ r.p.m.) until absorbance at $600 \mathrm{~nm}\left(\mathrm{OD}_{600}\right)$ was 4. To induce expression of recombinant protein, the culture temperature was raised to $42^{\circ} \mathrm{C}$ for $1 \mathrm{~h}$ and then dropped to $20^{\circ} \mathrm{C}$ for another hour. Cells were then harvested at
6000 r.p.m. for $5 \mathrm{~min}$ in a JA-14 rotor (Beckman Instruments Pty Ltd, Gladesville, NSW, Australia). The cell pellet was resuspended in $100 \mathrm{ml}$ extraction buffer (20 mM Tris, pH $8 \cdot 0,0 \cdot 2 \mathrm{mg} / \mathrm{ml}$ lysozyme, $0 \cdot 1 \%(\mathrm{v} / \mathrm{v})$ Tween-20) and incubated at $4{ }^{\circ} \mathrm{C}$ overnight. The sample was sonicated for $30 \mathrm{~s}$ prior to centrifugation at 14000 r.p.m. for $10 \mathrm{~min}$ in a JA-14 rotor at $4{ }^{\circ} \mathrm{C}$. The aqueous phase, containing the lysozyme wash, was retained. The cell pellet was then washed twice with ice-cold water and this osmotic shock wash was retained. Each wash consisted of resuspending the pellet in $100 \mathrm{ml}$ ice-cold water followed by incubation on ice for $1 \mathrm{~h}$. Following centrifugation at 14000 r.p.m. for $10 \mathrm{~min}$ in a JA-14 rotor at $4{ }^{\circ} \mathrm{C}$, the $\mathrm{pH}$ of the aqueous phase was adjusted by the addition 
of $10 \mathrm{ml} 10 \times$ TBS buffer, $\mathrm{pH} 8(0.08 \% \mathrm{NaCl}, 0.002 \%$ $\mathrm{KCl}, 0 \cdot 03 \%$ Tris base, $\mathrm{pH} 7 \cdot 4)$. The lysozyme and osmotic shock washes were pooled and constitute the periplasmic fraction of the cells. Sodium azide (0.05\%), phenylmethylsulphonyl fluoride $(23 \mu \mathrm{g} / \mathrm{ml})$ and EDTA $(50 \mathrm{mM})$ were added to the periplasmic extract, which was then ready for purification.

\section{Purification of recombinant IGFBP-3 fragments}

The IGFBP-3 fragments, N-88 and C-165, were isolated from the periplasmic extracts by affinity chromatography on an anti-FLAG column using the FLYTAG antibody. The affinity column was prepared by immobilising FLYTAG antibody onto Mini-Leak Low resin (Kem-EnTec, Copenhagen, Denmark) according to the manufacturer's instructions. Periplasmic extracts were directly loaded onto a $20 \mathrm{ml}$ anti-FLAG column pre-equilibrated in phosphate-buffered saline (PBS) ( $\mathrm{pH} \mathrm{7.4)} \mathrm{containing}$ $0.05 \%$ sodium azide. Bound proteins were eluted with Immunopure Gentle $\mathrm{Ag} / \mathrm{Ab}$ Elution Buffer (Pierce Chemical Co.) and the peak fractions were pooled, dialysed against $\mathrm{PBS} / 0 \cdot 05 \%$ azide $(\mathrm{pH} 7 \cdot 4)$ and concentrated by ultrafiltration over a $3000 \mathrm{kDa}$ cutoff membrane. Samples were analysed and further purified by sizeexclusion chromatography on a calibrated Superdex 200 HR 30/10 column (Pharmacia Biotech) at a flow rate of $0.5 \mathrm{ml} / \mathrm{min}$. The fractions corresponding to the monomeric fragments of $\mathrm{N}-88$ and $\mathrm{C}-165$ were pooled and concentrated prior to further analysis. Protein concentration was determined spectrophotometrically using an extinction coefficient for a $0 \cdot 1 \%(\mathrm{w} / \mathrm{v})$ solution at $280 \mathrm{~nm}$ of 2.9 for the amino-terminal domain and 0.9 for the carboxyl-terminal domain, calculated from the protein sequences (Gill \& von Hippel 1989). The concentration of active IGFBP in the recombinant protein samples was determined by an RIA specific for human IGFBP-3 as previously described (Baxter \& Martin 1986).

Protein samples were analysed by SDS-PAGE using 15\% Tris/glycine gels and Western blot analyses using the FLYTAG antibody were performed as described previously (Kortt et al. 1994). The $\mathrm{N}$-terminal sequence analysis of the $\mathrm{N}-88$ and $\mathrm{C}-165$ monomeric peaks isolated by Sephadex 200 chromatography was determined, after SDS-PAGE and transfer of the protein bands onto ProBlott PVDF membrane (Perkin-Elmer Applied Biosystems), using a Hewlett Packard Protein Sequencer (G1000A).

\section{Biosensor binding analyses}

The BIAcore biosensor (BIACORE AB), which uses surface plasmon resonance detection and permits real-time interaction analysis of two interacting species (Jonsson et al. 1993, Karlsson 1994), was used to measure the binding kinetics of the N-88 and C-165 fragments of IGFBP-3 with IGF-I and IGF-II. Both IGF-I and IGF-II $(20 \mu \mathrm{g} / \mathrm{ml}$ in $10 \mathrm{mM}$ sodium acetate buffer, $\mathrm{pH} 4.5$ ) were immobilised onto a CM-5 sensor chip using the Amine coupling kit (BIACORE AB) as described previously. The immobilisation was carried out at $25^{\circ} \mathrm{C}$ at a flow rate of $5 \mu \mathrm{l} / \mathrm{min}$ and 625 resonance units (RU) IGF-I and 277 RU IGF-II were coupled on separate flow cells. Fragments N-88 and C-165 were also immobilised using the Amine coupling kit. Fragment N-88 could not be successfully immobilised even at $\mathrm{pH} 3.0$ by amine coupling. Fragment C-165 was immobilised $(100 \mu \mathrm{g} / \mathrm{ml}$ in $10 \mathrm{mM}$ sodium acetate buffer, $\mathrm{pH} 3 \cdot 0,360 \mathrm{RU})$ at a flow rate of $2 \mu \mathrm{l} / \mathrm{min}$ but was found to be inactive.

Binding experiments were performed in HBS buffer (10 mM Hepes, 0.15 M NaCl, $3 \cdot 4 \mathrm{mM}$ EDTA, 0.005\% surfactant $\mathrm{P} 20, \mathrm{pH} 7 \cdot 4$ ) at a constant flow rate of $5 \mu \mathrm{l} / \mathrm{min}$. Aliquots $(30-50 \mu \mathrm{l})$ were sequentially injected over the IGF-I and IGF-II surfaces. Each surface was regenerated with a $10 \mu \mathrm{l}$ aliquot of $100 \mathrm{mM} \mathrm{HCl}$ with negligible loss of binding activity. Samples for binding analyses were prepared by gel filtration on Superdex 75 or Superose 12 to remove any cleavage products or higher molecular mass aggregates that may have formed on storage. RIA was used to determine the concentration of biologically active binding fragment in the affinity-purified protein preparations (Baxter \& Martin 1986). The binding data was evaluated with BIAevaluation 3.0.2 software (BIACORE AB) as described previously (Kortt et al. 1999).

\section{Solution IGF- and ALS-binding assays}

The binding characteristics of the amino- and carboxylterminal IGFBP-3 constructs were also examined using solution IGF- and ALS-binding assays as described previously (Baxter et al. 1992).

\section{Results}

Expression and purification of human IGFBP-3 N- and C-domain fragments

Plasmid vectors expressing amino acid residues 1-88 (designated as pPOW3/N-88) or 165-264 (designated as pPOW3/C-165) of human IGFBP-3 were constructed as shown in Fig. 1. These plasmid vectors were transformed into E. coli strain TOP10F' for protein expression, which was monitored by Western blot analysis using the antiFLAG antibody, FLYTAG, to detect the FLAG peptide tag. A typical Western blot analysis of pPOW3/N-88 and pPOW3/C-165 expression is shown in Fig. 2. Following induction for $2 \mathrm{~h}, \mathrm{pPOW} 3 / \mathrm{N}-88$ (Fig. 2A) expressed a protein of about $11 \mathrm{kDa}$ consistent with the expected molecular mass of the $\mathrm{N}-88$ fragment of IGFBP-3. In contrast, $\mathrm{pPOW} 3 / \mathrm{C}-165$ yielded a major product with an apparent molecular mass of $18 \mathrm{kDa}$ and a minor product of 

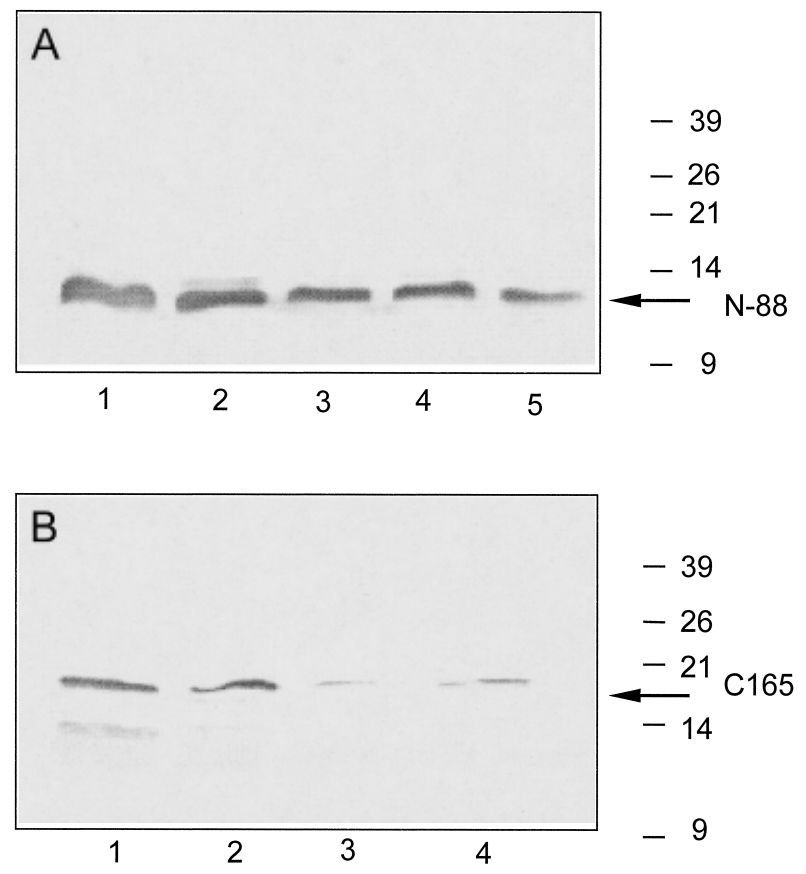

Figure 2 Western blot analysis following SDS-PAGE (15\% polyacrylamide gels) of IGFBP-3 fragments N-88 and C-165 expressed in $E$. coli host TOP10F' using heat-inducible vector pPOW3. After heat induction at $42{ }^{\circ} \mathrm{C}$, cultures were allowed to grow for $2 \mathrm{~h}$ at room temperature, fractionated as described in Materials and Methods and samples separated on 15\% SDS-PAGE and transferred to nitrocellulose for blotting with anti-FLAG FLYTAG antibody. (A) Fragment N-88 expression product. Lane 1, $2 \mathrm{~h}$ post induction; lane 2, lysozyme wash; lane 3, first osmotic shock; lane 4, pooled soluble extract; lane 5, anti-FLAG affinity column eluate. (B) Fragment C-165 expression product. Lane 1, $2 \mathrm{~h}$ post induction; lane 2, lysozyme wash; lane 3 pooled soluble extract and lane 4 anti-FLAG affinity column eluate. The migration positions of the BenchMark Prestained Protein Ladder (Gibco BRL Life Technologies) are shown on the right of each panel.

apparent molecular mass of $13 \mathrm{kDa}$ (Fig. 2B). The calculated molecular mass of expressed fragment C-165 is 13815 Da suggesting that the C-165 fragment exhibits anomalous mobility on SDS-PAGE and that the smaller fragment observed on the gel probably represents a proteolytic cleavage product with a truncated amino-terminus as it is detectable by the anti-FLAG antibody.

Both fragments were isolated in a single step by affinity chromatography directly from the periplasmic extracts and the oligomeric state of the expressed proteins was analysed by gel filtration. Affinity-purified N-88 fragment contained predominantly monomer with some dimer and a mixture of higher molecular mass forms (Fig. 3A). Affinity-purified C-165 fragment contained mainly monomer with a small amount of high molecular mass aggregate (Fig. 3C). The monomeric component of each fragment was separated from the higher molecular mass forms by gel filtration on Superdex 200 and shown to elute

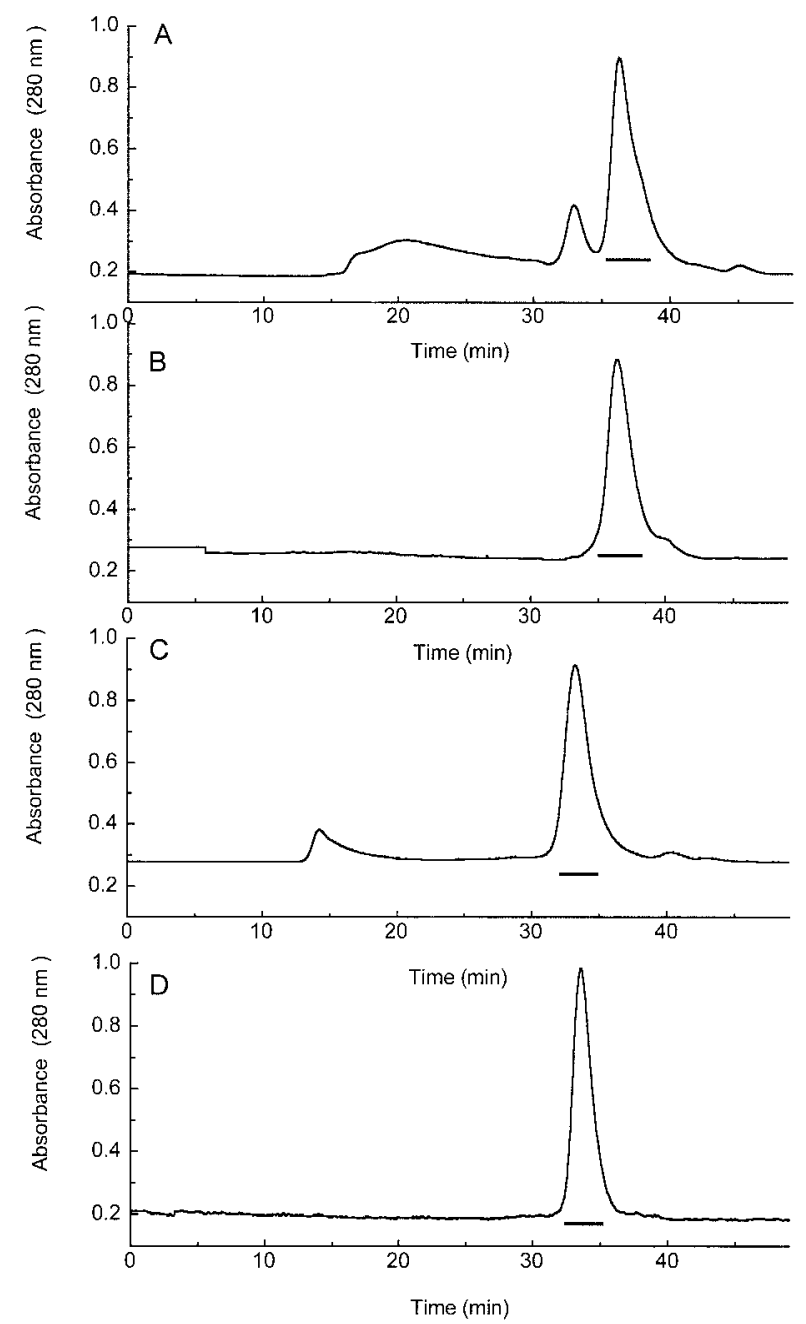

Figure 3 Size-exclusion chromatography on a calibrated Superdex 200 column HR30/10 of recombinant IGFBP-3 N-88 and C-165 fragments. (A) Elution profile of affinity-purified recombinant $\mathrm{N}-88$ fragment. (B) Elution profile of the $\mathrm{N}-88$ monomer isolated by gel filtration (A). (C) Elution profile of affinity-purified recombinant C-165 fragment. (D) Elution profile of C-165 monomer isolated by gel filtration $(\mathrm{C})$.

as a single symmetrical peak on rechromatography (Fig. 3B and D). SDS-PAGE analysis of the N-88 monomer gave a single band of $11 \mathrm{kDa}$ while the $\mathrm{C}-165$ monomer peak migrated as a major band of about $18 \mathrm{kDa}$ with only a trace of the $13 \mathrm{kDa}$ band observed in periplasmic fractions (data not shown). Amino-terminal sequence analysis of the monomers of $\mathrm{N}-88$ and $\mathrm{C}-165$ showed that the signal sequence had been correctly processed and the aminoterminal sequences of N-88 (GASSGGLGP) and C-165 (SQSTDTQNFS) matched the predicted sequence expected for these fragments of human IGFBP-3 (Fig. 1B). 


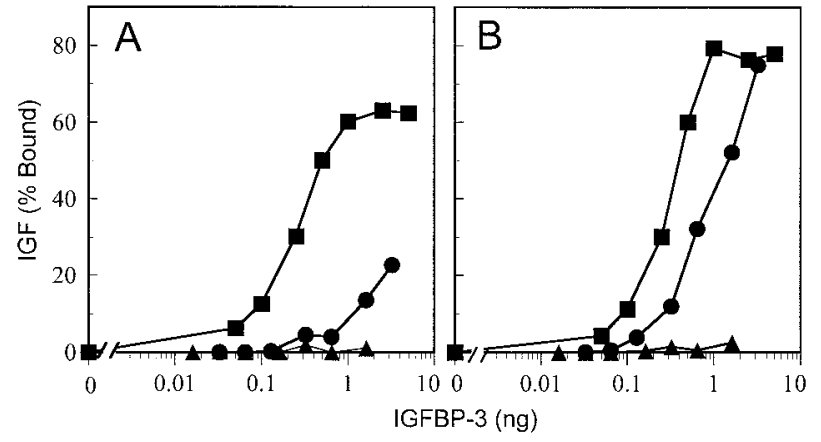

Figure 4 Binding of IGFBP-3 and N-88 and C-165 fragments to IGF-I or IGF-II in solution demonstrating the formation of the binary complexes. Binding of $\left[{ }^{125} \mathrm{I}\right] \mathrm{IGF}-\mathrm{I}(\mathrm{A})$ and $\left[{ }^{125} \mathrm{I}\right] \mathrm{IGF}-\mathrm{II}(\mathrm{B})$ to increasing immunoreactive amounts, determined by RIA, of plasma-derived IGFBP-3 ( $\mathbf{\square}), \mathrm{N}-88(\mathbf{\Delta})$ or C-165 (-) is shown. The binding curves are representative of two independent measurements for each IGF analogue.

Although the expressed IGFBP-3 N-88 and C-165 fragments were soluble and stable as expected for correctly folded recombinant proteins, the possibility of misfolding of these protein domains on bacterial expression is high due to the high content of cysteine residues $(\mathrm{N}-88$ contains twelve cysteine residues and C-165 has six) and number of disulfide bonds that have to be formed to yield biologically active protein. Thus the concentration of biologically active binding fragment in these purified protein preparations was estimated by RIA specific for human IGFBP-3 on the assumption that the antibody only recognises proteins which are correctly folded. The proportion of presumably correctly folded content of N-88 and $\mathrm{C}-165$ in the recombinant preparations was found to be surprisingly low with only $0 \cdot 15 \%$ and $0 \cdot 10 \%$ of the protein active respectively. Nevertheless, the possibility clearly remains that the RIA may be underestimating the concentration of biologically active fragment although low yields of biologically active material have been documented for a number of recombinant protein preparations (Zeder-Lutz et al. 1999).

\section{Binding of N-88 and C-165 to IGF in solution}

The IGF-binding characteristics of the fragments N-88 and C-165 in solution IGF-binding assays were performed as described in Materials and Methods. Dose-response curves for the binding of the fragments N-88 and C-165 to either $\left[{ }^{125} \mathrm{I}\right] \mathrm{IGF}-\mathrm{I}$ (Fig. 4A) or $\left[{ }^{125} \mathrm{I}\right] \mathrm{IGF}-\mathrm{II}$ (Fig. 4B) were determined. In the case of the $\mathrm{N}-88$, little or no detectable binding was observed to either IGF-I or IGF-II. This suggests that either the affinity of the N-88/IGF interaction is too low to be detected in this solution assay format or there is no interaction between N-88 and IGF. In contrast, the C-165 fragment showed IGF-I and IGF-II binding activity, indicating that the C-165/IGF inter- action is of higher affinity than that for N-88. Furthermore, the C-165 fragment binds to IGF-I less effectively than it binds to IGF-II; compared with the full-length IGFBP-3 purified from human serum, C-165 binds to IGF-I and IGF-II approximately 20-fold and 3-fold less effectively respectively.

\section{Biosensor analysis of N-88 and C-165 binding to IGF}

The binding of full-length IGFBP-3 (purified from human serum) to immobilised IGF-I was characterised by a very slow dissociation rate. Estimation of the rate constants gave a $\mathrm{k}_{a}=1 \cdot 1 \times 10^{-5} \mathrm{M}^{-1} \mathrm{~s}^{-1}$ and $\mathrm{k}_{d}$ of $\geq 1 \cdot 0 \times 10^{-6} \mathrm{~s}^{-1}$ indicating that the association constant, $\mathrm{K}_{a}$, is $\sim 1 \times 10^{11} \mathrm{M}^{-1}$ (Fig. 5). This estimate is similar to that reported by Wong et al. (1999) and is comparable with our previous estimate of $1.5 \times 10^{11} \mathrm{M}^{-1}$ using solution-binding assays (Firth et al. 1998).

Binding interactions between fragments N-88 or C-165 to immobilised IGF-I or IGF-II were also demonstrated by BIAcore biosensor analysis. Representative sensorgrams for the binding of N-88 and C-165 to IGF-I (Fig. 6A and C) and IGF-II (Fig. 6B and D) are shown. The binding data were fitted to the Langmuir 1:1 binding model using the fitting procedures in BIAevaluation 3.0.2 to calculate kinetic constants. The association and dissociation rate constants and equilibrium binding constants determined from these data are summarised in Table 1.

The association rates for the binding of C-165 to both IGF-I and IGF-II (Fig. 6C and D) were observed to be linear under the conditions used, and proportional to the active protein concentration (data not shown). This indicates that these rates are apparently mass transfer limited, and hence a meaningful $\mathrm{k}_{a}$ value could not be determined for these data. In contrast, the association rates for binding of N-88 to immobilised IGF-I and IGF-II did not appear to be mass transfer limited. The $\mathrm{k}_{a}$ values indicate that the $\mathrm{N}-88$ fragment associates with IGF-II $\left(4.54 \times 10^{5} \mathrm{M}^{-1} \mathrm{~s}^{-1}\right)$ three times faster than it associates with IGF-I $(1.47 \times$ $\left.10^{5} \mathrm{M}^{-1} \mathrm{~s}^{-1}\right)$.

Analysis of the dissociation rate data, which are independent of analyte concentration, gave a good fit to the $1: 1$ Langmuir binding model consistent with a 1:1 interaction between each fragment and IGFs. Some differences were observed in the interaction with the IGFs; fragment N-88 dissociates $1 \cdot 8$-fold faster from immobilised IGF-I than IGF-II, while the dissociation rate of C-165 from IGF-I was $2 \cdot 9$-fold faster than from IGF-II. Dissociation rate from IGF-I and IGF-II was 50- and 75-fold faster, respectively, for N-88 compared with C-165 (Table 1). Compared with full-length IGFBP-3, the dissociation rates of N-88 and C-165 are at least four orders of magnitude faster. The estimated rate constants for the interaction of N-88 with IGF-I and IGF-II (Table 1) indicate a decrease in binding affinity of about three orders of magnitude by $\mathrm{N}-88$ for both IGFs when compared with 


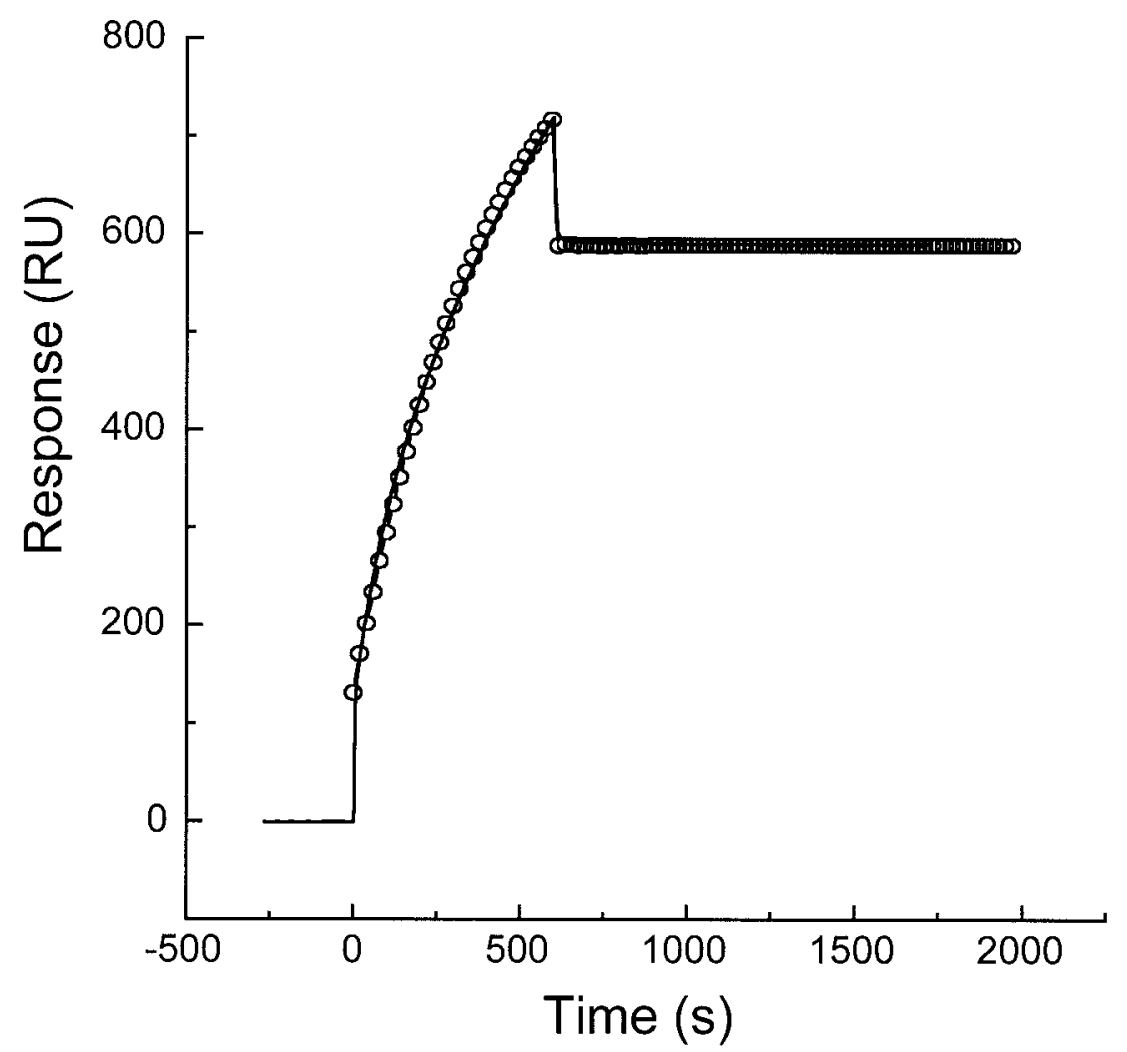

Figure 5 Binding interaction of native human IGFBP-3 with immobilised IGF-I. The sensorgram shows the binding profile (solid line) on injection of IGFBP-3 (at $33 \mathrm{nM}$ ) over a surface of immobilised IGF-I at a flow rate of $5 \mu \mathrm{l} / \mathrm{min}$. The fit to the 1:1 Langmuir binding model is shown by the circles.

full-length IGFBP-3. This decrease in affinity is due to a much faster dissociation rate constant for the single domain fragment and, presumably, the loss of contribution of bivalent binding of the intact IGFBP-3 molecule. Furthermore, the much slower dissociation rate observed for the C-165 fragment suggests that this domain contributes more to the binding affinity of the parent IGFBP-3 than the N-88 fragment, which shows a rapid dissociation rate.

The interaction in the opposite orientation between the N-88 and C-165 fragments and IGF-I and IGF-II could not be studied in the BIAcore. The N-88 fragment could not be immobilised via amine chemistry due to its extremely low $\mathrm{pI}$ and while the C-165 fragment was successfully immobilised, its orientation was such that it was no longer functional, i.e. the IGF-binding site(s) was masked.

Since C-165 could form binary complexes with either IGF-I or IGF-II and it has been shown previously that the ALS-binding site on IGFBP-3 resides in the C-terminal region (Firth et al. 1998), we examined the ability of C-165 to form ternary complexes with ALS in the presence of either IGF-I or IGF-II. Solution-binding assays were performed in which $\left[{ }^{125} \mathrm{I}\right]$ ALS was incubated with increasing concentrations of C-165 in the presence of $50 \mathrm{ng}$ of either IGF-I or IGF-II. As shown in Fig. 7, C-165 binds ALS in a dose-dependent manner and the binding curves obtained were similar regardless of the IGF present. However, there was an approximately 20-fold reduction in potency when compared with the natural full-length protein.

\section{Discussion}

Although binding analyses using various IGF mutants have revealed residues in the IGFs that are important for the IGF-IGFBP interaction (Baxter et al. 1992, Bach et al. 1993, Dubaquie \& Lowman 1999), less is known about the linear sequences or specific residues of any IGFBP that are responsible for IGF binding. We and others have shown previously that synthetic rat and human aminoterminal fragments of IGFBP-3 retain IGF-binding activity, though with greatly reduced affinity (Hashimoto et al. 1997, Firth et al. 1998, Vorwerk et al. 1998). The decreased affinity of similar amino-terminal IGFBP-3 fragments identified in normal and pregnancy serum has 

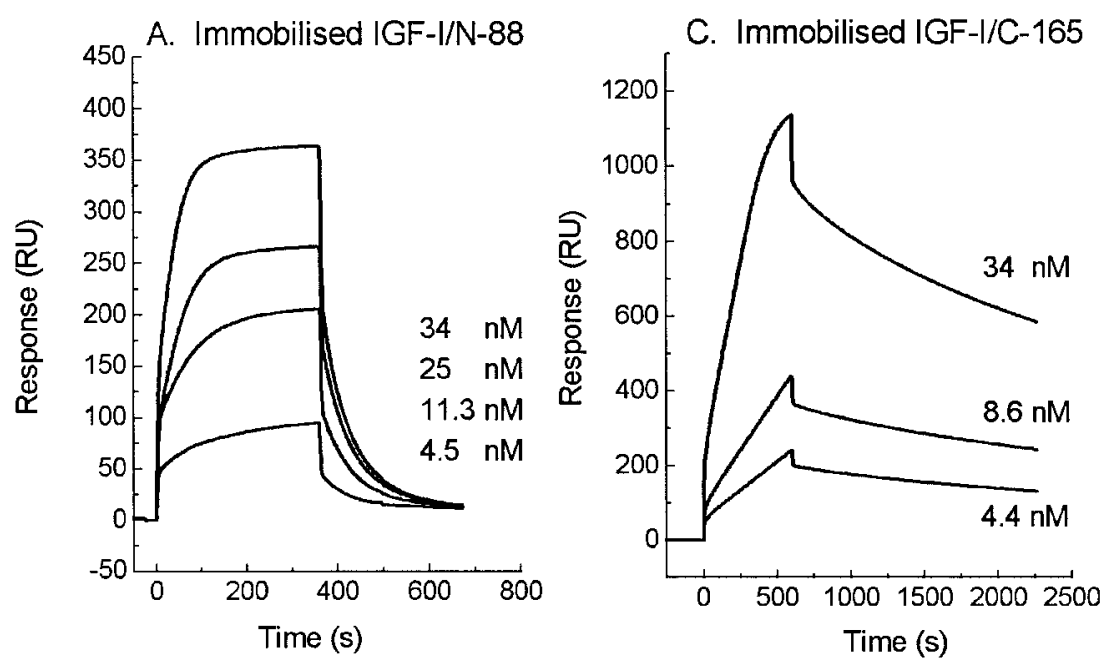

B. Immobilised IGF-II/N-88
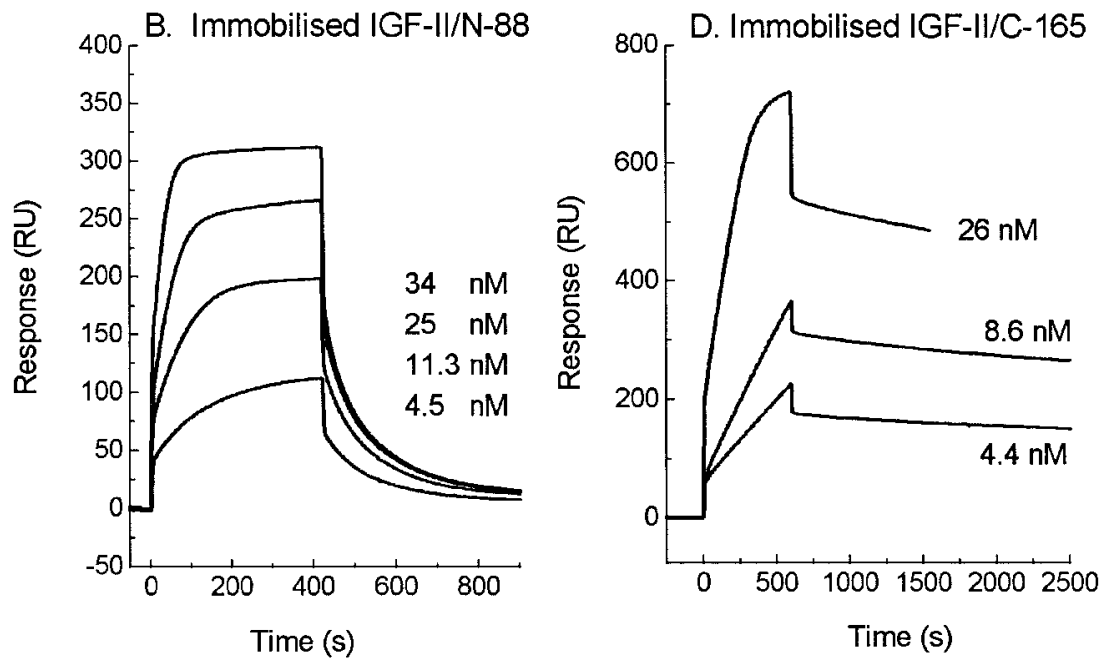

Figure 6 Binding interaction of recombinant IGFBP-3 N-88 and C-165 fragments. Sensorgrams show the binding of fragment N-88 to immobilised IGF-I (A) and IGF-II (C) and the binding of fragment C-165 to immobilised IGF-I (B) and IGF-II (D). The sensorgrams were runs at a flow rate of $5 \mu \mathrm{l} / \mathrm{min}$ with an injection volume of $35 \mu \mathrm{l}$. Concentrations of analyte are indicated on the individual sensorgrams. The surface was regenerated with $10 \mu \mathrm{l} 0 \cdot 1 \mathrm{M}$ $\mathrm{HCl}$ after each cycle.

been proposed to result in increased IGF bioavailability (Hossenlopp et al. 1990, Zapf et al. 1990). Brinkman et al. (1991a) showed that deletion of residues 1-60 of IGFBP-1 destroyed its IGF binding, but did not identify the key residues involved. Kalus et al. (1998) identified $\mathrm{Va}^{49}$, $\mathrm{Tyr}^{50}, \mathrm{Pro}^{62}$ and $\mathrm{Lys}^{68}{ }_{-} \mathrm{Leu}^{74}$ as key IGF-binding residues in the human IGFBP-5 amino-terminal domain, and concluded that these residues constituted the sole highaffinity site in this protein. Residues in the same region of bovine IGFBP-2 and human IGFBP-4 have also been shown to be important (Hobba et al. 1996, 1998, Qin et al.
1998). The corresponding residues in IGFBP-3 are $\mathrm{Il}^{56}$, $\mathrm{Tyr}^{57}$, Pro ${ }^{69}$ and $\mathrm{Arg}^{75}$-Leu ${ }^{81}$, which must therefore be considered as prime candidates for IGF-binding residues of IGFBP-3. It was recently shown that substitution of Lys ${ }^{68}$, Pro ${ }^{69}, \mathrm{Leu}^{70}, \mathrm{Leu}^{73}$ and $\mathrm{Leu}^{74}$ of IGFBP-5 to Asn, Gln, Gln, Gln and Gln and substitution of Arg ${ }^{69}$, Pro ${ }^{70}$, Leu $^{71}$, $\mathrm{Leu}^{74}$ and $\mathrm{Leu}^{75}$ to Ser, Ala, Ser, Gln and Gly resulted in at least 1000-fold reduction in affinity for IGF-I (Imai et al. 2000). These studies confirm that an important IGFbinding determinant is located within the amino-terminal region of IGFBP-3. 
Table 1 Apparent kinetic rate constants and equilibrium binding constants for the interaction between IGFBP-3 N-88 and C-165 domain fragments to immobilised IGF-I or IGF-II. Values are means \pm S.D.

\begin{tabular}{|c|c|c|c|}
\hline & $\mathbf{k}_{\mathbf{a}}\left(\times 10^{5} \mathrm{M}^{-1} \mathrm{~s}^{-1}\right)$ & $\mathbf{k}_{\boldsymbol{d}}\left(\times 10^{-2} \mathrm{~s}^{-1}\right)$ & $\mathbf{K}_{\mathbf{A}}\left(\times 10^{7} \mathrm{M}^{-1}\right)$ \\
\hline \multicolumn{4}{|c|}{ Immobilised IGF-I } \\
\hline N-88 & $1 \cdot 47 \pm 0 \cdot 16$ & $1 \cdot 26 \pm 0 \cdot 28$ & $1 \cdot 03 \pm 0.08$ \\
\hline C-165 & Not determined ${ }^{a}$ & $0.027 \pm 0.003$ & - \\
\hline \multicolumn{4}{|c|}{ Immobilised IGF-II } \\
\hline N-88 & $4 \cdot 54 \pm 1 \cdot 42$ & $0.71 \pm 0.061$ & $6 \cdot 16 \pm 1 \cdot 43$ \\
\hline C-165 & Not determined ${ }^{a}$ & $0.0094 \pm 0.002$ & - \\
\hline
\end{tabular}

${ }^{a}$ The association rates for the binding of fragment C-165 to both IGF-I and IGF-II were not independent of the analyte concentration, indicating that the rate measured was not a second order rate constant and hence no information was obtained on the association rate constants of these interactions and $k_{a}$ values were not calculated.

Other studies have similarly pointed to the importance of IGFBP carboxyl-terminal residues in IGF binding (Brinkman et al. 1991b, Forbes et al. 1998, Qin et al. 1998), with carboxyl-terminal fragments of IGFBP-2 shown to retain considerable binding (Wang et al. 1988, Ho \& Baxter 1997). However, to date there is no evidence that corresponding fragments of IGFBP-3 are active. In this study, we have expressed the amino- and carboxyl-terminal domains of human IGFBP-3 separately. The C-165 protein contains 20 amino acids from the non-conserved central region of IGFBP-3; this extra sequence appears to contribute to either an increased

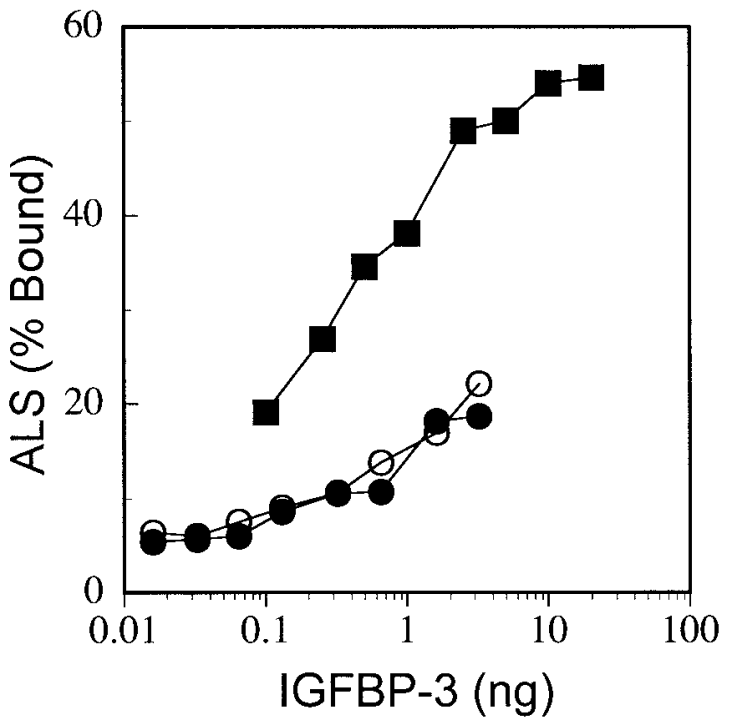

Figure 7 Binding of IGFBP-3 C165 fragment to ALS in the presence of IGF-I or IGF-II to form of a ternary complex. Binding of $\left[{ }^{125} \mathrm{I}\right] \mathrm{ALS}$ to increasing concentrations of C-165 in the presence of $50 \mathrm{ng}$ of either IGF-I (O) or IGF-II $(\mathbf{)})$ is shown. For comparison, the ALS-binding curve of plasma-derived IGFBP-3 ( $\mathbf{\square})$ in the presence of $50 \mathrm{ng}$ IGF-I is also shown. efficiency of synthesis or the conformational stability of the expressed protein since expression of a construct without this sequence (i.e. amino acid residues 185-264), which represents the conserved carboxyl-terminal region, was not detectable (data not shown). When analysed by solution-binding assays, there was no detectable specific binding of N-88 to IGFs, as previously shown for the same peptide expressed in Chinese hamster ovary $(\mathrm{CHO})$ cells (Firth et al. 1998). In contrast, C-165 bound IGF-I and IGF-II specifically. There has been one preliminary report in which a recombinant IGFBP-3 carboxyl-terminal fragment (residues 147-264) expressed by yeast cells was shown to bind to IGF-I by size-exclusion chromatography (Spencer \& Chan 1995); however, no binding affinities were determined. An equivalent IGFBP-2 carboxylterminal fragment (residues 181-289), which was purified from milk, showed similar binding characteristics to C-165 in that it had approximately tenfold and fourfold reduction in IGF-I and IGF-II affinity respectively (Ho \& Baxter 1997).

The detection of IGF-binding activity by either natural or recombinant fragments of IGFBP is method-dependent. For example, we have previously shown that an $\mathrm{N}-88$ equivalent recombinant protein expressed by transfected $\mathrm{CHO}$ cells did not bind IGF when analysed by either solution-binding assays or IGF-ligand blots but was detected by affinity labelling (Firth et al. 1998). In this study, we have chosen to use sensitive BIAcore technology to analyse the interactions between $\mathrm{N}-88$ or C-165 with IGF-I or -II. Although binding affinities and association rate constants obtained from this method are dependent on the concentration of the binding protein, the estimated dissociation rate constants are independent of the concentration of the binding protein and should be correct. However, our inability to determine precisely the concentration of active protein introduces a degree of uncertainty with respect to the absolute values reported for the association rate constants and binding constants for the IGFBP-3 fragments. 
The binding kinetics of full-length IGFBP-3 to both IGF-I and IGF-II have been studied previously (Heding et al. 1996, Wong et al. 1999). A more recent study (Wong et al. 1999) used the same configuration as our present study (i.e. IGF-I immobilised on the sensor surface and IGFBP-3 in solution) and obtained a similar equilibrium association constant of $\mathrm{K}_{a}=1.8 \times 10^{11} \mathrm{M}^{-1}$. In contrast, Heding et al. (1996) obtained an equilibrium association constant of $\mathrm{K}_{a}=4.3 \times 10^{9} \mathrm{M}^{-1}$ when they looked at the interaction between IGF-I in solution and IGFBP-3 immobilised on the sensor surface.

The kinetics of association of N-88 to IGF is similar to the kinetics of association of insulin to IGFBP-3 observed by Heding et al. (1996). This study showed that the binding of N-88 to both IGF-I and IGF-II was similar, with fast association and slow non-first-order dissociation kinetics, and an equilibrium $\mathrm{K}_{d}$ for IGF-I of $251 \mathrm{nM}$. This is significant from two points of view, given the considerable amino acid sequence homology between the IGFs and insulin. Not only has insulin previously been shown to bind to the amino-terminal region of IGFBP-3 (Vorwerk et al. 1998), but also to mac25 or IGFBP-related protein-1, a protein with $\mathrm{N}$-terminal sequence homology to the IGFBPs (Yamanaka et al. 1997).

The present study is the first to demonstrate the binding of a carboxyl-terminal IGFBP-3 fragment, C-165, to ALS in the presence of IGF. This is significant in that it suggests that the C-165-IGF binary complex is sufficient to form the binding site for ALS. However, it is possible that IGF is not essential for the interaction between C-165 and ALS. Although the apparent ALS affinity was considerably reduced, there appears to be no difference in affinity when IGF-I is present compared with IGF-II (both in excess concentration). This contrasts with the finding that C-165 only had $5 \%$ of IGF-I binding activity compared with $\sim 30 \%$ of IGF-II binding activity, when radioligands were used at tracer concentrations. We have previously shown that the ALS-binding site of IGFBP-3 and IGFBP-5 resides within the carboxyl-terminal domains (Firth et al. 1998, Twigg et al. 1998). Using site-directed mutagenesis, we have implicated five contiguous residues ( $\left.\mathrm{K}^{228} \mathrm{GRKR}\right)$, in the carboxyl-terminal region, of IGFBP-3 in ALS binding since substitution of these five residues resulted in $90 \%$ loss of ALS binding. However, the non-total loss in ALS affinity and the demonstration that C-165 has retained some ALS-binding affinity would suggest that regions of IGFBP-3, apart from the carboxyl-terminal amino acid residues 165-264, must be involved in contributing to the binding site directly or indirectly by stabilising the conformation of the binding site. It was recently demonstrated that there is a second binding domain for ALS in the central region of IGFBP-5 (Twigg et al. 2000).

In conclusion, we have shown using IGFBP-3 fragments that there are independent IGF-binding sites in the $\mathrm{N}$ - and $\mathrm{C}$-terminal domains of the protein. The IGF-binding site in the carboxyl-terminal region is a higher affinity site than the one in the N-terminal region. In addition, the carboxyl-terminal binding site binds IGF-II with higher affinity than IGF-I. We have also shown that the carboxyl-terminal fragment of IGFBP-3 can form ternary complexes with ALS and IGF, thus confirming that the ALS-binding site on IGFBP-3 resides within the carboxyl-terminal region.

\section{References}

Bach LA, Hsieh S, Sakano K, Fujiwara H, Perdue JF \& Rechler MM 1993 Towards identification of a binding site on insulin-like growth factor-II for IGF-binding proteins. Advances in Experimental Medicine and Biology 343 55-61.

Baxter RC 1997 Molecular aspects of insulin-like growth factor binding proteins. Advances in Molecular and Cellular Endocrinology 1 123-159.

Baxter RC \& Martin JL 1986 Radioimmunoassay of growth hormone-dependent insulin-like growth factor binding protein in human plasma. Journal of Clinical Investigation 78 1504-1512.

Baxter RC, Martin JL \& Beniac VA 1989 High molecular weight insulin-like growth factor binding protein complex. Purification and properties of the acid-labile subunit from human serum. Journal of Biological Chemistry 264 11843-11848.

Baxter RC, Bayne ML \& Cascieri MA 1992 Structural determinants for binary and ternary complex formation between insulin-like growth factor-I (IGF-I) and IGF binding protein-3. Journal of Biological Chemistry 267 60-65.

Brinkman A, Kortleve DJ, Schuller AG, Zwarthoff EC \& Drop SLS 1991 a Site-directed mutagenesis of the N-terminal region of IGF binding protein 1; analysis of IGF binding capability. FEBS Letters $291264-268$.

Brinkman A, Kortleve DJ, Zwarthoff EC \& Drop SLS $1991 b$ Mutations in the C-terminal part of insulin-like growth factor (IGF)-binding protein-1 result in dimer formation and loss of IGF binding capacity. Molecular Endocrinology 5 987-994.

Dubaquie Y \& Lowman HB 1999 Total alanine-scanning mutagenesis of insulin-like growth factor I (IGF-I) identifies differential binding epitopes for IGFBP-1 and IGFBP-3. Biochemistry 38 6386-6396.

Firth SM \& Baxter RC 1999 Characterisation of recombinant glycosylation variants of insulin-like growth factor binding protein-3. Journal of Endocrinology 160 379-387.

Firth SM, Ganeshprasad U \& Baxter RC 1998 Structural determinants of ligand and cell surface binding of insulin-like growth factor binding protein-3. Journal of Biological Chemistry 273 2631-2638.

Forbes BE, Turner D, Hodge SJ, McNeil KA, Forsberg G \& Wallace JC 1998 Localisation of an insulin-like growth factor (IGF) binding site of bovine IGF binding protein-2 using disulfide mapping and deletion mutation analysis of the C-terminal domain. Journal of Biological Chemistry 273 4647-4652.

Gill SC \& von Hippel PH 1989 Calculation of protein extinction coefficients from amino acid sequence data. Analytical Biochemistry 182 319-326.

Hashimoto R, Ono M, Fujiwara H, Higashihashi N, Yoshida M, Enjoh-Kimura T \& Sakano K 1997 Binding sites and binding properties of binary and ternary complexes of insulin-like growth factor-II (IGF-II), IGF-binding protein-3, and acid-labile subunit. Journal of Biological Chemistry 272 27936-27942.

Heding A, Gill R, Ogawa Y, De Meyts P \& Shymko RM 1996 Biosensor measurement of the binding of insulin-like growth factors I and II and their analogues to the insulin-like growth factor-binding protein-3. Journal of Biological Chemistry 271 13948-13952.

Ho PJ \& Baxter RC 1997 Characterization of truncated insulin-like growth factor-binding protein-2 in human milk. Endocrinology 138 3811-3818 
Hobba GD, Forbes BE, Parkinson EJ, Francis GL \& Wallace JC 1996 The insulin-like growth factor (IGF) binding site of bovine insulin-like growth factor binding protein-2 (bIGFBP-2) probed by iodination. Journal of Biological Chemistry 271 30529-30536.

Hobba GD, Lothgren A, Holmberg E, Forbes BE, Francis GL \& Wallace JC 1998 Alanine screening mutagenesis establishes tyrosine 60 of bovine insulin-like growth factor binding protein-2 as a determinant of insulin-like growth factor binding. Journal of Biological Chemistry 273 19691-19698.

Hossenlopp P, Segovia B, Lassarre C, Roghani M, Bredon M \& Binoux M 1990 Evidence of enzymatic degradation of insulin-like growth factor binding proteins in the '150-K' complex during pregnancy. Journal of Clinical Endocrinology and Metabolism 71 797-805.

Imai Y, Moralez A, Andag U, Clarke JB, Busby WH Jr \& Clemmons DR 2000 Substitutions for hydrophobic amino acids in the $\mathrm{N}$-terminal domains of IGFBP-3 and -5 markedly reduce IGF-I binding and alter their biologic actions. Journal of Biological Chemistry 275 18188-18194.

Jonsson U, Fagerstam L, Lofas S, Stenberg E, Karlsson R, Frostell A, Markey F \& Schindler F 1993 Introducing a biosensor based technology for real-time biospecific interaction analysis. Annales de Biologie Clinique 51 19-26.

Kalus W, Zweckstetter M, Renner C, Sanchez Y, Georgescu J, Grol M, Demuth D, Schumacher R, Dony C, Lang K \& Holak TA 1998 Structure of the IGF-binding domain of the insulin-like growth factor-binding protein-5 (IGFBP-5): Implications for IGF and IGF-I receptor interactions. EMBO Journal 17 6558-6572.

Karlsson R 1994 Real-time competitive kinetic analysis of interactions between low-molecular-weight ligands in solution and surface-immobilised receptors. Analytical Biochemistry 221 142-151.

Kortt AA, Malby RL, Caldwell JB, Gruen LC, Ivancic N, Lawrence MC, Howlett GJ, Webster RG, Hudson PJ \& Colman PM 1994 Recombinant anti-sialidase single-chain variable fragment antibody: Characterisation, formation of dimer and higher-molecular-mass multimers and the solution of the crystal structure of the single-chain variable fragment/sialidase complex. European Journal of Biochemistry 221 151-157.

Kortt AA, Nice E \& Gruen LC 1999 Analysis of the binding of the Fab fragment of monoclonal antibody NC10 to influenza virus N9 neuraminidase from tern and whale using the BIAcore biosensor: Effect of immobilisation level and flow rate on kinetic analysis. Analytical Biochemistry 273 133-141.

Power BE \& Hudson PJ 2000 Synthesis of high avidity antibody fragments (scFv multimers) for cancer imaging. Journal of Immunological Methods 242 193-204.

Qin XZ, Strong DD, Baylink DJ \& Mohan S 1998 Structure-function analysis of the human insulin-like growth factor binding protein-4. Journal of Biological Chemistry 273 23509-23516.

Rajaram S, Baylink DJ \& Mohan S 1997 Insulin-like growth factorbinding proteins in serum and other biological fluids: regulation and functions. Endocrine Reviews 18 801-831.
Sambrook J, Fritsch EF \& Maniatis T 1989 Molecular Cloning. A Laboratory Manual. Cold Spring Harbor, New York: Cold Spring Harbor Laboratories Press.

Sommer A, Spratt SK, Tatsuno GP, Tressel T, Lee R \& Maack CA 1993 Properties of glycosylated and non-glycosylated human recombinant IGF binding protein-3 (IGFBP-3). Growth Regulation 3 46-49.

Spencer EM \& Chan K 1995 A 3-dimensional model for the insulin-like growth factor binding proteins (IGFBPs); supporting evidence using the structural determinants of the IGF binding site on IGFBP-3. Progress in Growth Factor Research 6 209-214.

Twigg SM \& Baxter RC 1998 Insulin-like growth factor (IGF) binding protein-5 forms an alternative ternary complex with IGFs and the acid-labile subunit. Journal of Biological Chemistry 273 6074-6079.

Twigg SM, Kiefer MC, Zapf J \& Baxter RC 1998 Insulin-like growth factor-binding protein 5 complexes with the acid-labile subunit. Role of the carboxyl-terminal domain. Journal of Biological Chemistry 273 28791-28798.

Twigg SM, Kiefer MC, Zapf J \& Baxter RC 2000 A central domain binding site in insulin-like growth factor binding protein-5 for the the acid-labile subunit. Endocrinology 141 454-457.

Vorwerk P, Yamanaka Y, Spagnoli A, Oh YM \& Rosenfeld RG 1998 Insulin and IGF binding by IGFBP-3 fragments derived from proteolysis, baculorvirus expression and normal human urine. Journal of Clinical Endocrinology and Metabolism 83 1392-1395.

Wang J-F, Hampton B, Mehlman T, Burgess WH \& Rechler MM 1988 Isolation of a biologically active fragment from the carboxy terminus of the fetal rat binding protein for insulin-like growth factors. Biochemical and Biophysical Research Communications 157 718-726.

Wong MS, Fong CC \& Yang M 1999 Biosensor measurement of the interaction kinetics between insulin-like growth factors and their binding proteins. Biochimica et Biophysica Acta 1432 293-301.

Yamanaka Y, Wilson EM, Rosenfeld RG \& Oh Y 1997 Inhibition of insulin receptor activation by insulin-like growth factor binding proteins. Journal of Biological Chemistry 272 30729-30734.

Zapf J, Kiefer M, Merryweather J, Masiarz F, Bauer D, Born W, Fischer JA \& Froesch ER 1990 Isolation from adult human serum of four insulin-like growth factor (IGF) binding proteins and molecular cloning of one of them that is increased by IGF-I administration and in extrapancreatic tumor hypoglycemia. Journal of Biological Chemistry 265 14892-14898.

Zeder-Lutz G, Benito A \& Van Regenmortel MH 1999 Active concentration measurements of recombinant biomolecules using biosensor technology. Journal of Molecular Recognition 12 300-309.

Received in final form 20 November 2000 Accepted 28 November 2000 